\title{
Short-term Effect of Emotional Intelligence Learning on Sports Directors' Emotional Intelligence Acquisition and Retention: A Focus Group Discussion Report
}

\author{
Isaac Akinloye OYEWUMI \\ Department of Human Kinetics, Sports and Health Education, Faculty of Education, Lagos State University, \\ Ojo. \\ Email ID: akinloyeakinloye@yahoo.com
}

\begin{abstract}
This is a short-term report of a longitudinal study designed to examine efficacy of focus group discussion on the status, acquisition, short-term and long-term retention of emotional intelligence among sports directors consequent of exposure to Emotional Intelligence Learning. The study investigated inclination to acquire Emotional Intelligence (EI) as a psychological criterion for wellness attainment in participants after exposure to EIL. Emotional Intelligence (EI) implies the intimate transaction of inner and outer forces, physical and social, that fuse to lead man to behave as he does. The study adopted SelfRegulation Theory for its theoretical base and conceptualized $\boldsymbol{E I}$ as acquired skill in occupational and career dispensations, job performance, and satisfaction. The study employed mixed-method research design. Thus, the quasi-experimental research design: One-Group, Pre-Posttest $(G P--O--T-O)$ was mixed with a focus group discussion. Emotional Competence Inventory (ECI-U) a 360 18-question item that assesses the handling of emotions in life and work settings (Boyatzis, 1994) was employed to assess participants' entry emotional status (pre-test) while the Self-Assessment Questionnaire (Boyatzis, et. al., (1996) a 28-question item was adapted and used to collect data on short-term of Emotional Intelligence (post-test) data. SPSS Statistics v. 23 Matched pairs $t$-test indicated pretest descriptive result $(N=10$, Mean $=30.70, S D=5.83)$ and posttest $(N=10$, Mean $=42.90, S D=7.40)$; and inferential [T-Test $=-4.199, d f=9, p=.002]$. Findings indicated significant preparedness for acquisition and retention of EI as regards wellness attainment at the workplace by participants. It was recommended that $\boldsymbol{E I}$ skill training should be extended to all cadres (rank and file) of personnel in the Ministries of Sports, Youth and Social Development.
\end{abstract}

Key Words: Emotional Intelligence, Emotional Intelligence Learning, Focus Group Discussion, ShortTerm Retention,

\section{Introduction}

Man is a social animal. Perhaps man's greatest quality is his capacity for creating and giving symbolic meanings and values to intangible and abstract things. By making use of this capacity, he is able to extend himself so that he can participate in groups far removed in time and space, and share with others his thoughts, beliefs, hopes, fears, concerns, expectations and intentions. So intricately is man enmeshed in a socio-cultural setting, that it is meaningless to speak of man's psychological behaviour apart from this setting. Man as a social animal, nurses and monitor his need of group belongingness. The remarkable dominance of human beings over other creatures and their ability to control physical forces is a result, in part, of their ability to work together in groups to achieve more than the total work of the individuals involved

\subsection{Emotions in the workplace}

Well-being, welfare or wellness is a general term for the condition of an individual or group, for example their social, economic, psychological, spiritual or medical state; a high level of well-being means in some sense the individual or group's experience is positive, while low well-being is associated with negative happenings. 
Emotions in the workplace play a large role in how an entire organization communicates within itself and to the outside world. "Events at work have real emotional impact on staff. The consequences of emotional states in the workplace, both behavioural and attitudinal, have substantial significance for individuals, groups, and society" (Weiss, 2002). Positive emotions in the workplace help employees obtain favourable outcomes including achievement, job enrichment and higher quality social context (Staw, Sutton, \& Pelled, 1994). "Negative emotions, such as fear, anger, stress, hostility, sadness, and guilt, however increase the predictability of workplace deviance,"(Lee, \& Allen, 2002) and how the outside world views the organization.

Emotions normally are associated with specific events or occurrences and are intense enough to disrupt thought processes (Brief, \& Weiss. 2002). There can be many consequences for allowing negative emotions to affect our general attitude or mood at work. "Emotions and emotion management is a prominent feature of organizational life. It is crucial "to create a truly personally satisfying and publicly observable and desirable emotional display as a part of a job role" (Mann, 1999).

Foremost of the reasons of our value as applied scientists is to have a grip of the many reasons to be interested in human emotions in the workplace, understand the role it plays and aspire to increase human wellness. Working in this realm require the metacognition of the psychologist in view of the fact, that, rather than being objective, wellness is subjectively defined/perceived by people in terms of their affective reactions to organizational events

\subsection{Self-Regulation Theory}

The theory of self-regulation posits that as a social species, humans have a fundamental need to belong (Gallagher \& Frith, 2003). This need encourages behaviour consistent with being a good group member. Being a good group member requires the capacity for self-regulation, which allows people to alter or inhibit behaviour that would place them at risk for group exclusion. Self-regulation requires four psychological components:

- First, people need to be aware of their behaviour so as to gauge it against societal norms.

- Second, people need to understand how others are reacting to their behaviour so as to predict how others will respond to them.

- The idea in bullet two above necessitates a third mechanism, which detects threat, especially in complex social situations.

- $\quad$ Finally, there needs to be a mechanism for resolving discrepancies between self-knowledge and social expectations or norms, thereby motivating behaviour to resolve any conflict that exists.

Cross-species affective neuroscience studies confirm that primary-process of emotional feelings are organized within primitive subcortical regions of the brain that are anatomically, neuro-chemically, and functionally. Among the most consequential behavioural and neural changes that have occurred over the course of phylogeny (the evolution of a genetically related group of organisms as distinguished from the development of the individual organism) is the capacity to regulate emotion. Humans acquire complex capabilities to regulate their emotions. Indeed, lack of competence in emotion regulatory skills is associated with a variety of behavioural problems.

Inhibition is a core feature of self-regulation, which refers to the process by which people initiate, adjust, interrupt, stop, or otherwise change thoughts, feelings, or actions in order to effect realization of personal goals or to maintain current standards. At the broadest level, self-regulation refers to intentional or purposeful acts that are directed from within the person. From this perspective, learning, physiology, and culture predispose certain behaviour, thoughts, or emotions in specific circumstances, but self-regulation allows people to change or overcome them. Although all humans have an impressive capacity for self-regulation, failures are common, and people lose control of their behaviour in a wide variety of circumstances. Such failures are an important cause of several contemporary societal problems - extremism, sexual predation, addiction, fanaticism, corruption and infidelity, to name but a few. Shielding people of these problems and associated, sometimes debilitative repercussions command emotional intelligence.

\subsection{Emotional Intelligence (EI)}

Emotional intelligence (EI) is a relatively new and growing area of behavioural research. The concept resonates with zeitgeist (spirit of the age or spirit of the time which is the intellectual fashion 
or dominant school of thought that typifies and influences the culture of a particular period in time) emphasizing the importance of self-awareness and understanding, redressing a perceived imbalance between intellect and emotion in the life of the collective Western mind. Emotional intelligence also connects with several cutting-edge areas of psychological science, including the neuroscience of emotion, self-regulation theory, studies of metacognition, and the search for human cognitive abilities beyond "traditional" academic intelligence (Mayer, Salovey \& Caruso, 2000a).

Emotional Intelligence (EI) refer to the mental processes involved in the recognition, the use, understanding, and management of one's own and others' emotional states to solve problems and regulate behaviour (Mayer, \& Salovey, 1997). That implies that emotional intelligence is ability-or competency-based skill to be acquired (Saarni, 1988), as distinguished from being rooted in personality attribute (Mayer, Caruso, \& Salovey, 2000) for theoretical and empirical distinctions. Emotional intelligence from this tradition refers to an individual's capacity to reason about emotions and to process emotional information in order to enhance cognitive processes

Emotional Intelligence (EI) is a term used to describe the ability of an individual to recognize their own and other people's emotions, to discriminate between different feelings and label them appropriately, and to use emotional information to guide thinking and behavior (Mayer, \& Salovey, 1997).

For the purpose of this article, I have deliberately avoided the academic endeavour of extrapolating on the diverse and differentiated opinions on the concept EI. Nonetheless, it is worth the mention that there are several models of EI. Goleman's own model that is now considered a mixed model that combines what have subsequently been modelled separately as ability EI and trait EI. Thus, Goleman defined Emotional Intelligence as the array of skills and characteristics that drive leadership performance Goleman, (1998). The trait model was developed by Konstantin Vasily Petrides in 2001. It "encompasses behavioural dispositions and self-perceived abilities and is measured through self-report" Cherniss, (2001). The ability model, developed by Peter Salovey and John Mayer in 2004, focuses on the individual's ability to process emotional information and use it to navigate the social environment Salovey, Mayer, \& Caruso, (2004),.

Studies have shown that people with high EI have greater mental health, exemplary job performance, and more potent leadership and adaptability skills. What is most important though is the understanding that emotional intelligence is a skill and it can be developed. It is not exclusively inherent in us; emotional intelligence can be taught, learnt and continually developed. However, an educational package to teach this concept is not yet off-the-shelve commonality it ought to be.

\subsection{Statement of Problem}

The problem of this study therefore, is an examination of the efficacy of Emotional Intelligence Learning on participants' inclination to emotional intelligence acquisition and retention.

\subsection{Methods and Participants}

The study employed mixed-method research design. Thus, the One-Group, Pre-Posttest (GP--O--T-O) quasi-experimental research design was mixed with a focus group discussion. The collected data was analyzed with the aid of Matched Pairs t-test. The discussion was patterned on the conventional teaching-learning classroom atmosphere but more relaxed to facilitate meta-researcher-subjects' interaction. The session was a flexible and highly adaptable 2-hour psychology lesson on a six-phase template comprised of: general introduction, a brief $x$-ray of notable individuals in the league of emotionally intelligent followed with ideas on the four variables of Daniel Goleman's quadrant model of EI: Self-Awareness, Self-Management, SocialAwareness and Relationship-Management. Sample was a cohort of an intact group of directors of sports drafted to participate in the annual training/workshop. Participants were Ten (10). Directors (7 or 70\%) and Assistant Directors (3 or 30\%), nine males (90\%) and one female (10\%) from ten states ministries of youth, sports and social development. Participants' age ranges from forty-six (46) to fifty-three (53). Two research assistants were employed. One of the research assistants moderated the qualitative aspect of the study by serving as the moderator of the focus group discussion session. The second assistant handled the pre-test and post-test instruments used to collect quantitative data 


\section{Results and Discussion of Findings}

SPSS package was used to compute the matched pair's t-test as presented in tables 1 and 2 below:

TABLE I: Descriptive Statistics- Paired Samples t-test

\begin{tabular}{|cc|c|c|c|c|}
\hline & & Mean & $\mathrm{N}$ & Std. Deviation & Std. Error Mean \\
\hline \multirow{2}{*}{ Pair 1 } & Pre-Test & 30.7000 & 10 & 5.83190 & 1.84421 \\
& Post-Test & 42.9000 & 10 & 7.40045 & 2.34023 \\
\hline
\end{tabular}

TABLE II: Paired Samples T-Test

\begin{tabular}{|c|c|c|c|c|c|c|c|c|}
\hline & \multicolumn{5}{|c|}{ Paired Differences } & \multirow[b]{3}{*}{$\mathrm{T}$} & \multirow[b]{3}{*}{ df } & \multirow[b]{3}{*}{ Sig. (2-tailed) } \\
\hline & \multirow[b]{2}{*}{ Mean } & \multirow{2}{*}{$\begin{array}{l}\text { Std. } \\
\text { Deviation }\end{array}$} & \multirow{2}{*}{$\mid \begin{array}{ll}\text { Std. } & \text { Error } \\
\text { Mean } & \end{array}$} & \multicolumn{2}{|c|}{$\begin{array}{l}95 \% \text { Confidence Interval } \\
\text { of the Difference }\end{array}$} & & & \\
\hline & & & & Lower & Upper & & & \\
\hline $\begin{array}{l}\text { Pair } \text { Pre-Test } \\
1 \quad \text { Post-Test }\end{array}$ & -12.20000 & 9.18695 & 2.90517 & -18.77195 & -5.62805 & -4.199 & 9 & .002 \\
\hline
\end{tabular}

A paired sample T-Test was conducted to examine the short-term effect of focus group discussion on participants' retention of acquired emotional intelligence in view of wellness attainment at the place of work. The analysis showed that there is a significant impact of focus group discussion on participants' short-term retention of acquired emotional intelligence in view of wellness attainment at the place of work in both descriptive and inferential analyses. Pretest $(\mathrm{N}=10$, Mean=30.70, $\mathrm{SD}=5.83)$ and posttest $(\mathrm{N}=10, \mathrm{Mean}=42.90$, $\mathrm{SD}=7.40)$; [T-Test $=-4.199, \mathrm{df}=9, \mathrm{p}=.002]$.

This finding of the study agrees with Rousseau (2004) as well as Knights \& Kennedy (2005) discoveries that employees will catch in on the opportunity to get well and along with their peers if employers/organizations facilitate an enabling environment for such development.

\section{Summary, Conclusion and Recommendations}

Evidence abounds that people with high emotional intelligence have greater mental health, exemplary job performance, and more potent leadership skills as well as positive adaptability. Emotional intelligence is a skill and it can be developed. It is not exclusively inherent in us; emotional intelligence can be taught, learnt and continually upgraded. Findings of the paper lend credence to this fact and the conclusion here is that the Emotional Intelligence Learning (EIL) impacts positively on the propensity for acquisition and retention of EI. Therefore, it is hereby recommended that the research be replicated in other sectors of both private and public organizations, designed in such a way to benefit not only those at the managerial level but the rank and file as well.

\section{References}

[1] Boyatzis, R. E. (1994) "Stimulating self-directed learning through the Managerial Assessment and Development Course," Journal of Management Education, 18(3)

https://doi.org/10.1177/105256299401800303 
[2] Boyatzis, R. E., Leonard, D., Rhee, K., \& Wheeler, J. V. (1996). Competencies can be developed, but not the way we thought. Capability, 2 (2). P. 25-41

[3] Brief, A. P. \& Weiss, M. H. (2002). Organizational Behavior: Affect in the Workplace. Annu. Rev. Psychol. 53, 279307. https://doi.org/10.1146/annurev.psych.53.100901.135156

[4] Gallagher H. L, Frith, C. D. (2003). Functional imaging of "theory of mind" Trends Cogn Sci. 7:77-83 https://doi.org/10.1016/S1364-6613(02)00025-6

[5] Goleman, D. (1998). Working With Emotional Intelligence. New York, NY. Bantum Books.

[6] Knights, J \& Kennedy, B (2005). Psychological Contract Violation: Impacts on Job Satisfaction and Organisational Commitment among Australian Senior Public servants. Applied HRM Research. 10(2).57-72.

[7] Lee, K, \& Allen, N. J. (2002). Organizational Citizenship Behavior and Workplace Deviance: The Role of Affect and Cognitions. Journal of Applied Psychology, 87(1), 131-142. https://doi.org/10.1037/0021-9010.87.1.131

[8] Mann, S. (1999). Emotion at work: to what extent are we expressing, suppressing, or faking it? European Journal of Work and Organizational Psychology, 8(3) 347-369 https://doi.org/10.1080/135943299398221

[9] Mayer, J.D., \& Salovey, P. (1997). What is emotional intelligence? In P. Salovey \&D.J. Sluyter (Eds.), Emotional development and emotional intelligence: Educational Implications (pp. 3-31). New York: Basic Books.

[10] Mayer, J.D., Caruso, D.R., \& Salovey, P. (2000). Selecting a measure of emotional intelligence: The case of ability scales. In R. Bar-On \& J.D.A. Parker (Eds.).The handbook of emotional intelligence (pp. 320-342). San Francisco: Jossey-Bass.

[11] Mayer, J.D., Salovey, P.R., \& Caruso, D.R. (2000a). Emotional intelligence as Zeitgeist, as personality, and as a mental ability. In R. Bar-On \& J.D.A. Parker (Eds.), The handbook of emotional intelligence (pp. 92-117). San Francisco: Jossey-Bass.

[12] Petrides, K, \& Furnham, A. (2001), "Trait Emotional Intelligence: Psychometric Investigation with Reference to Established Trait Taxonomies", European Journal of Personality: 425-448

https://doi.org/10.1002/per.416

[13] Rousseau D. (2004). Psychological Contracts in the Workplace: Understanding the Ties that Motivate. The Academy of Management Executive. 18(1).120-127. https://doi.org/10.5465/AME.2004.12689213

[14] Saarni, C. (1988). Emotional competence: How emotions and relationships become integrated. In R. A. Thompson (ed.), Nebraska Symposium on Motivation, 36: (115-182

[15] Salovey, P. \& Mayer, J. D. (1990). Emotional intelligence. Imagination, cognition, and personality, 9: 185-211 https://doi.org/10.2190/DUGG-P24E-52WK-6CDG

[16] Salovey, P; Mayer, J; Caruso, D (2004), "Emotional Intelligence: Theory, Findings, and Implications", Psychological Inquiry: 197-215 https://doi.org/10.1017/CBO9780511806582.019

[17] Staw, B.M., Sutton, R. S., Pelled, L.H. (1994). Employee positive emotion and avoidable outcomes at the workplace. Organization Science, 5(1) 51-70.

https://doi.org/10.1287/orsc.5.1.51

[18] Weiss, H. (2002). Introductory comments: Antecedents of Emotional Experiences at Work. Motivation and Emotion, 26(1), https://doi.org/10.1023/A:1015138223398 